\title{
SEISMIC FRAGILITY ANALYSES OF THE CABINET STORED ARTEFACTS WITH AND WITHOUT DAMPING METHOD
}

\author{
BAI WEN", DAI JUNWU, YANG YONGQIANG
}

Key Laboratory of Earthquake Engineering and Engineering Vibration, Institute of Engineering Mechanics, China Earthquake Administration Harbin 150080, China

e-mail: 781090853@qq.com(*corresponding author)

Keywords: Historical Structure, Masonry, Monitoring, Non-Destructive Inspection

\begin{abstract}
The Forbidden City, the former Chinese imperial palace, now houses the Palace Museum. It is not only famous for its splendid wooden palace complex, but also prestigious for the millions of precious artefacts stored. The Forbidden City is located in the center of Beijing, which is a high seismic hazard zone. Wooden structures usually perform well during earthquakes because of their large deformation and damping capacities. Meanwhile, most artefacts are fragile due to their delicate shapes and aging issues, and also due to their unanchored place form. Only a few of those artefacts are on exhibit, while most of the others are placed in cabinets and stored in warehouses. This paper focuses on seismic protection of these cabinet stored artefacts. Considering the tremendous amount and the rigorous requirements for moving the artefacts, base isolation is not a favored method. Using base isolation requires lifting the artefacts or cabinets while installing isolation bearings and this is very time consuming because of the rigorous requirements for moving artefacts. Also, artefact damage might happen during this process. Thirdly, much more spaces are required to accommodate the potential isolation deformation. Considering all these adverse aspects, this paper tries to use dampers to connect all adjacent cabinets to enhance the integrity and increase the damping ratio and thus protect the stored artefacts. This method is applicable for both new and existing cabinets. No artefact movement and extra space are required. All the dampers are installed with mechanical buckles and the whole installation is reversible. In order to validate the effectiveness of this method, shake table tests and finite element analyses based on practical cabinet layout with and without this damping method are designed and conducted. Ten ground motions are chosen and used to conduct fragility analyses. The cabinet sliding displacements are chosen as the damage index. Seismic fragility curves of the cabinets with and without dampers are plotted and compared. Results demonstrate the effectiveness of the proposed damping method.
\end{abstract}

\section{INTRODUCTION}

The Forbidden City, the former Chinese imperial palace, now houses the Palace Museum. Currently, more than 1.80 million pieces of artefacts are stored here. Dedicate shapes, brittle materials and aging issues are the major reasons why many of the artefacts are fragile. Meanwhile, Beijing, where the Forbidden City seats, is an earthquake prone area and thus the seismic damage risks of these invaluable treasures are high. Past earthquakes have 
demonstrated that tremendous damage to artefacts might be caused due to earthquakes. For example, during the 2008 Wenchuan earthquake, 4379 pieces of artefacts damaged, including 208 pieces of high value [1].

In order to reduce the potential adverse consequences caused by earthquakes, the dynamic response characteristics of artefacts and related floating items under earthquakes have been researched [2-11]. Many methods, both traditional and innovative, have been proposed and used [12-20]. As illustrated in Figure 1, nylon lines are used to offer extra constrains. Side support are added at the horse leg. Clamps are used to fix the vase and prevent the vase overturn. Meanwhile, modern methods like base isolation have also been used. The acceleration responses of the floating items could be significantly reduced.

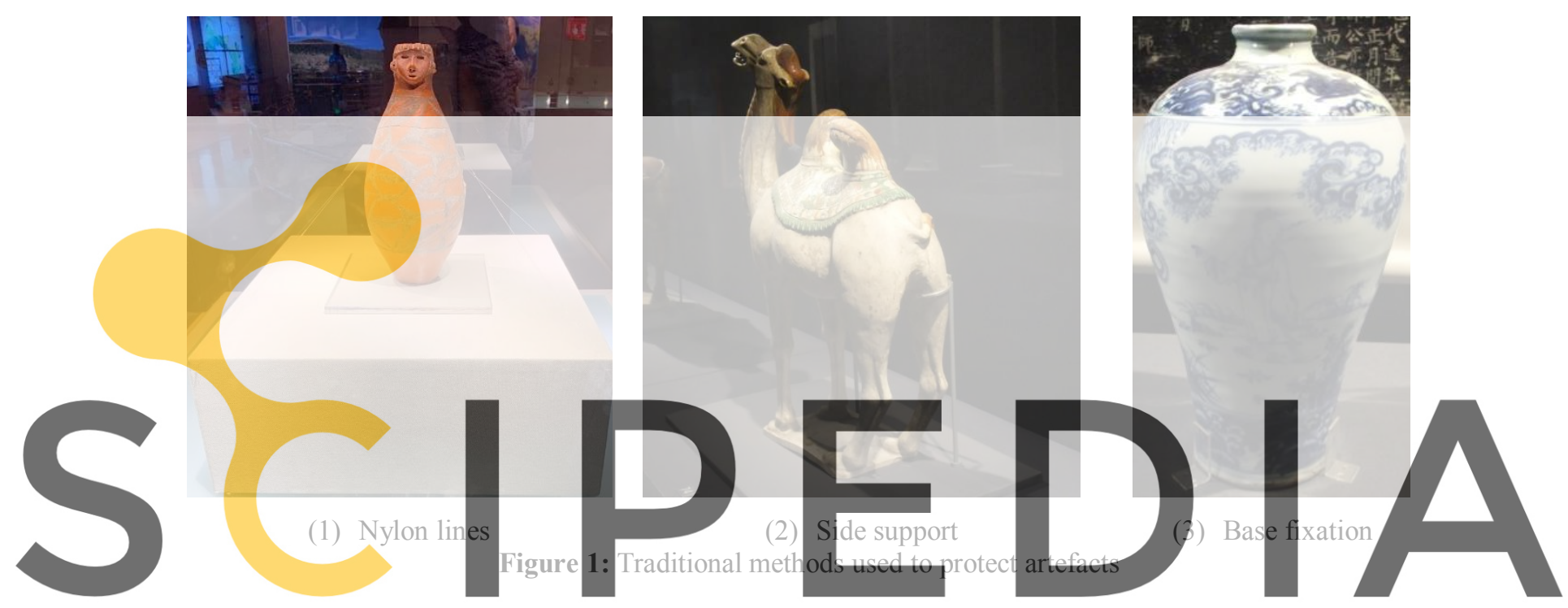

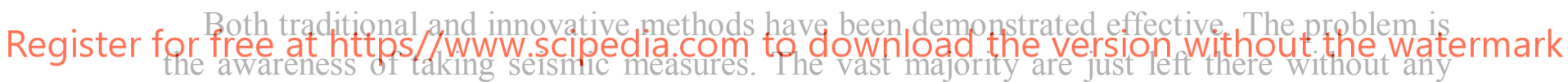
seismic protections. As for the numerous treasures in the Palace Museum, most of them have not been properly seismic protected. Another factor needs to be considered is that only a few of these artefacts are exhibited while most of the others are stored in the warehouse. It is not practical to take measure like nylon lines to protect each artefact because there is too much work, and this will cost years to complete. Besides, there are the risks that damage might be caused during the seismic protection process instead of earthquake itself. Base isolation has the same issues. The artefacts need to be moved during the application.

To protect these artefacts while avoiding unnecessary movement of these artefacts, a compromise method is advocated. Since most of the artefacts are placed in the cabinets and are stored in warehouses, silicon dampers are used to connect these cabinets to increase the system damping and integrity during earthquakes. The dynamic responses of the cabinets are expected to be decreased and those cabinet stored relics are to be protected. Numerical simulations and shake table tests are used to validate this method.

The numerical simulations are first presented and the shake table test results are then discussed. 


\section{NUMERICAL SIMULATIONS}

In the numerical simulation, the cabinets are established with SHELL element. The dampers are established with two-node combination damper element. The static friction coefficient is set as 0.2 and related dynamic friction coefficient is set as 0.16 . The models with and without dampers are shown in Figure 2. The plane layout is plotted in Figure 3. The size of the cabinets is $1200 \mathrm{~mm} \times 600 \mathrm{~mm} \times 2000 \mathrm{~mm}$ (height). There are two types of cabinets with different masses, which are $200 \mathrm{~kg}$ and $400 \mathrm{~kg}$, respectively. As for the damper parameters, the velocity exponent $\theta$ is 0.25 . The damping coefficient is set as $5.0 \mathrm{kN}(\mathrm{s} / \mathrm{m})^{\theta}$.

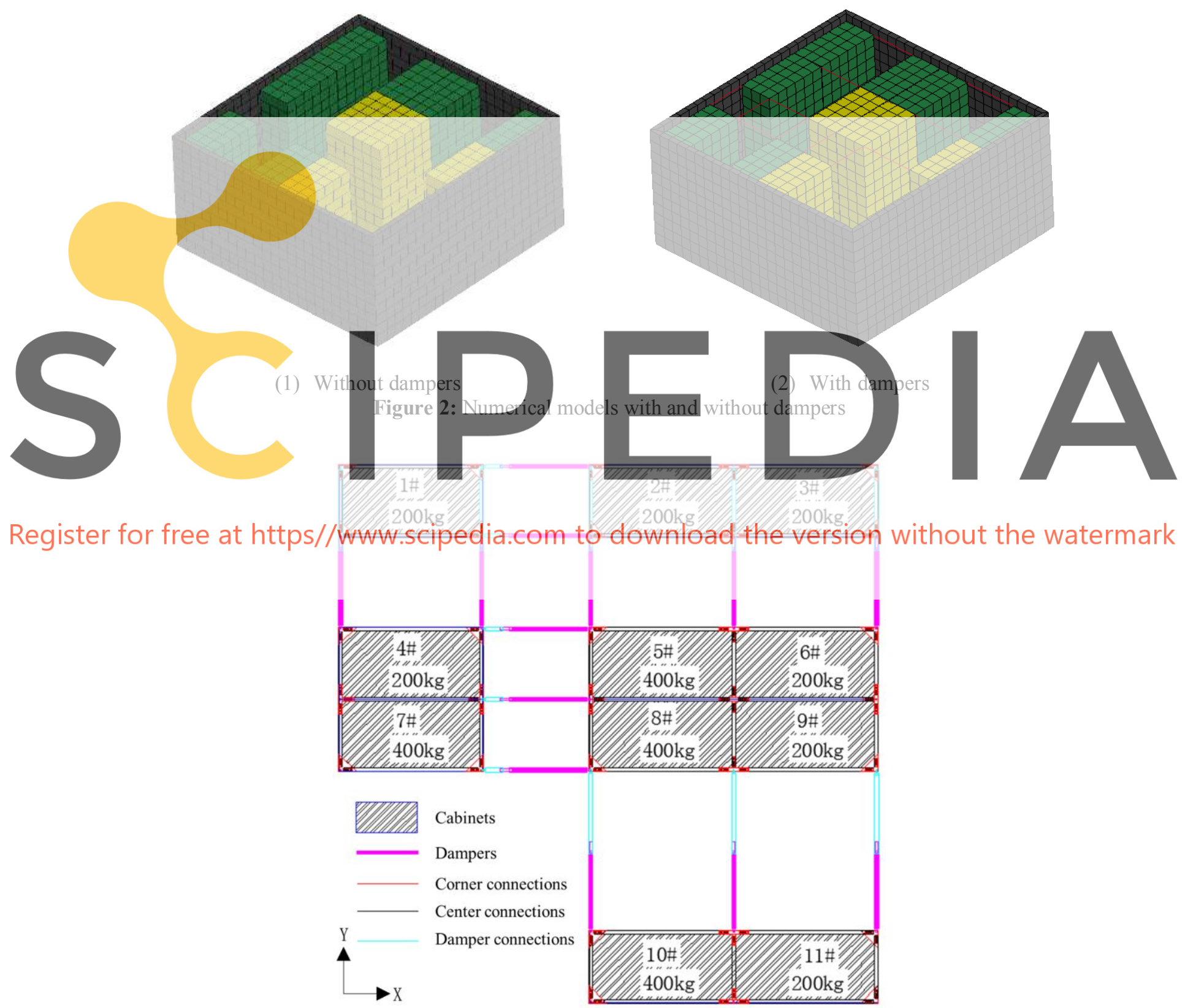

Figure 3: Plane layout of the cabinets 
Ten ground motions are chosen and used to conduct the fragility analyses. The information is listed in Table 1. Related acceleration spectra at X direction are plotted in Figure 4.

Table 1: Ground motions in the numerical analyses

\begin{tabular}{cccccc}
\hline No. & Earthquake name & Year & Station & Magnitude & Focal distance \\
\hline 01 & 'Mammoth Lakes-01' & 1980 & 'Long Valley Dam (Upr L Abut)' & 6.06 & 15.52 \\
\hline 02 & 'Chi-Chi, Taiwan' & 1999 & 'CHY036' & 7.62 & 44.74 \\
\hline 03 & 'Cape Mendocino' & 1992 & 'Rio Dell Overpass - FF' & 7.01 & 24.55 \\
\hline 04 & 'Imperial Valley-06' & 1979 & 'Delta' & 6.53 & 35.17 \\
\hline 05 & 'Kocaeli, Turkey' & 1999 & 'Yarimca' & 7.51 & 25.07 \\
\hline 06 & 'Imperial Valley-06' & 1979 & 'Calipatria Fire Station' & 6.53 & 58 \\
\hline 07 & 'Chi-Chi, Taiwan' & 1999 & 'CHY034' & 7.62 & 46.82 \\
\hline 08 & 'Chi-Chi, Taiwan' & 1999 & 'NST' & 7.62 & 89.2 \\
\hline 09 & 'Kocaeli, Turkey' & 1999 & 'Duzce' & 7.51 & 99.52 \\
\hline 10 & 'Trinidad' & 1980 & 'Rio Dell Overpass, E Ground' & 7.2 & 78.22 \\
\hline
\end{tabular}
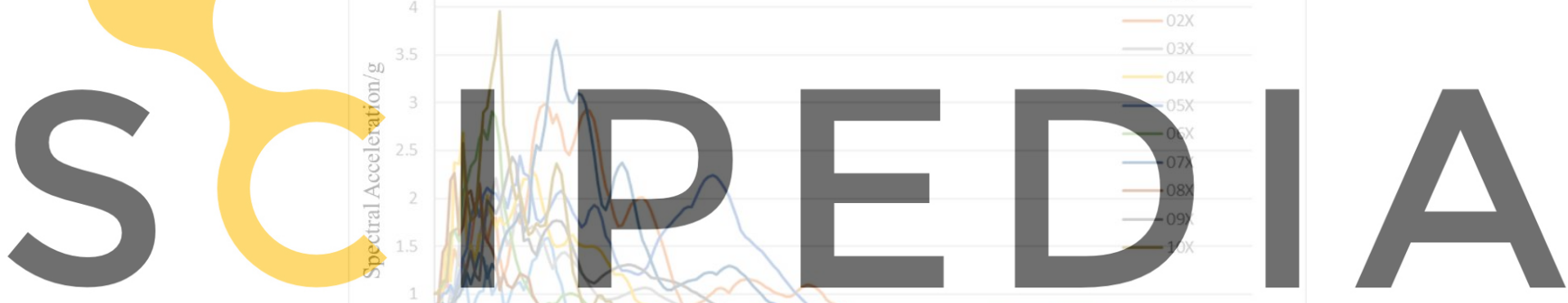

Register for free at https//www.scipedia.com to downtoad the version without the watermark

Period/s

Figure 4: Acceleration spectra of the 10 input ground motions at $\mathrm{X}$ direction

Table 2: Damage states

\begin{tabular}{ccc}
\hline Damage State & Description & Residual lateral dispalcement $(\mathrm{mm})$ \\
\hline DS0 & Intact & $(0,10]$ \\
\hline DS1 & Slight & $(10,100]$ \\
\hline DS2 & Moderate & $(100,200]$ \\
\hline DS3 & Severe & $(200$, above $)$ \\
\hline
\end{tabular}

In the numerical simulations, IDA analyses are conducted. The resolution of the PGA increment is $0.1 \mathrm{~g}$. The residual lateral displacement is chosen as the damage state (DS). Four DSs are defined and listed in Table 2. The numerical fragility results are listed in Table 3 . In the table, results at different DSs with and without the damping systems are listed, 
corresponding fragility curves are plotted in Figure 5.

It can be seen from the results that dampers are effective. The sliding distances are reduced with the use of dampers. As the PGA increases, the effectiveness also increases.

Table 3: Fragility results of the cabinets

\begin{tabular}{|c|c|c|c|c|c|c|c|}
\hline \multirow{2}{*}{$\mathrm{PGA} / \mathrm{g}$} & \multicolumn{3}{|c|}{ Damage probability without dampers } & \multirow{2}{*}{ PGA/g } & \multicolumn{3}{|c|}{ Damage probability with dampers } \\
\hline & DS1 & DS2 & DS3 & & DS1 & DS2 & DS3 \\
\hline 0.1 & $27.84 \%$ & $0.00 \%$ & $0.00 \%$ & 0.1 & $20.25 \%$ & $0.00 \%$ & $0.00 \%$ \\
\hline 0.2 & $62.54 \%$ & $0.01 \%$ & $0.00 \%$ & 0.2 & $54.42 \%$ & $0.00 \%$ & $0.00 \%$ \\
\hline 0.3 & $80.24 \%$ & $1.02 \%$ & $0.28 \%$ & 0.3 & $74.63 \%$ & $0.48 \%$ & $0.12 \%$ \\
\hline 0.4 & $89.01 \%$ & $8.87 \%$ & $2.92 \%$ & 0.4 & $85.42 \%$ & $5.10 \%$ & $1.42 \%$ \\
\hline 0.5 & $93.56 \%$ & $27.53 \%$ & $11.26 \%$ & 0.5 & $91.28 \%$ & $18.53 \%$ & $6.26 \%$ \\
\hline 0.6 & $96.06 \%$ & $50.69 \%$ & $25.56 \%$ & 0.6 & $94.59 \%$ & $38.56 \%$ & $15.98 \%$ \\
\hline 0.7 & $97.50 \%$ & $70.42 \%$ & $42.59 \%$ & 0.7 & $96.54 \%$ & $58.72 \%$ & $29.44 \%$ \\
\hline 0.8 & $98.36 \%$ & $83.80 \%$ & $58.72 \%$ & 0.8 & $97.72 \%$ & $74.64 \%$ & $44.17 \%$ \\
\hline 0.9 & $98.89 \%$ & $91.67 \%$ & $71.89 \%$ & 0.9 & $98.46 \%$ & $85.40 \%$ & $57.95 \%$ \\
\hline 1.0 & $99.24 \%$ & $95.89 \%$ & $81.61 \%$ & 1.0 & $98.93 \%$ & $91.97 \%$ & $69.55 \%$ \\
\hline 1.1 & $99.46 \%$ & $98.02 \%$ & $88.32 \%$ & 1.1 & $99.25 \%$ & $95.72 \%$ & $78.60 \%$ \\
\hline 1.2 & $99.61 \%$ & $99.07 \%$ & $92.74 \%$ & 1.2 & $99.46 \%$ & $97.77 \%$ & $85.30 \%$ \\
\hline 1.3 & $99.72 \%$ & $99.56 \%$ & $95.55 \%$ & 1.3 & $99.61 \%$ & $98.85 \%$ & $90.06 \%$ \\
\hline 1.4 & $99.79 \%$ & $99.80 \%$ & $97.30 \%$ & 1.4 & $99.71 \%$ & $99.41 \%$ & $93.37 \%$ \\
\hline 1.5 & $99.84 \%$ & $99.90 \%$ & $28.37 \%$ & 1.5 & $99.78 \%$ & $99.70 \%$ & $95.61 \%$ \\
\hline 1.6 & $99.88 \%$ & $99.96 \%$ & $99.02 \%$ & 1.6 & $99.840 \%$ & $99.85 \%$ & $97.11 \%$ \\
\hline 1.7 & $99.91 \%$ & $99.98 \%$ & $99.41 \%$ & 1.7 & $99.88 \%$ & $9.92 \%$ & $98.11 \%$ \\
\hline 1.8 & $99.93 \%$ & $99.99 \%$ & $99.65 \%$ & 1.8 & $99.90 \%$ & $99.96 \%$ & $98.76 \%$ \\
\hline 1.9 & $99.95 \%$ & $100.00 \%$ & $99.79 \%$ & 1.9 & $99.93 \%$ & $.98 \%$ & $99.1 \% \%$ \\
\hline 2.0 & $99.96 \%$ & $100.00 \%$ & $99.87 \%$ & 2.0 & & & \\
\hline 0.1 & $27.84 \%$ & $0.00 \%$ & $0.00 \%$ & 0.1 & $20.25 \%$ & $0.00 \%$ & $0.00 \%$ \\
\hline 0.2 & $62.54 \%$ & $0.01 \%$ & $0.00 \%$ & 0.2 & $54.42 \%$ & $0.00 \%$ & $0.00 \%$ \\
\hline
\end{tabular}

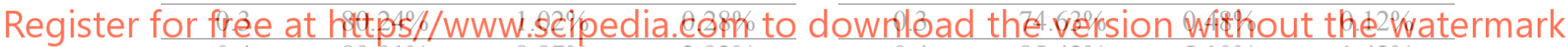

\begin{tabular}{|c|c|c|c|c|c|c|c|}
\hline & & & & & & & \\
\hline 0.5 & $93.56 \%$ & $27.53 \%$ & $11.26 \%$ & 0.5 & $91.28 \%$ & $18.53 \%$ & $6.26 \%$ \\
\hline 0.6 & $96.06 \%$ & $50.69 \%$ & $25.56 \%$ & 0.6 & $94.59 \%$ & $38.56 \%$ & $15.98 \%$ \\
\hline 0.7 & $97.50 \%$ & $70.42 \%$ & $42.59 \%$ & 0.7 & $96.54 \%$ & $58.72 \%$ & $29.44 \%$ \\
\hline 0.8 & $98.36 \%$ & $83.80 \%$ & $58.72 \%$ & 0.8 & $97.72 \%$ & $74.64 \%$ & $44.17 \%$ \\
\hline 0.9 & $98.89 \%$ & $91.67 \%$ & $71.89 \%$ & 0.9 & $98.46 \%$ & $85.40 \%$ & $57.95 \%$ \\
\hline 1.0 & $99.24 \%$ & $95.89 \%$ & $81.61 \%$ & 1.0 & $98.93 \%$ & $91.97 \%$ & $69.55 \%$ \\
\hline 1.1 & $99.46 \%$ & $98.02 \%$ & $88.32 \%$ & 1.1 & $99.25 \%$ & $95.72 \%$ & $78.60 \%$ \\
\hline 1.2 & $99.61 \%$ & $99.07 \%$ & $92.74 \%$ & 1.2 & $99.46 \%$ & $97.77 \%$ & $85.30 \%$ \\
\hline 1.3 & $99.72 \%$ & $99.56 \%$ & $95.55 \%$ & 1.3 & $99.61 \%$ & $98.85 \%$ & $90.06 \%$ \\
\hline 1.4 & $99.79 \%$ & $99.80 \%$ & $97.30 \%$ & 1.4 & $99.71 \%$ & $99.41 \%$ & $93.37 \%$ \\
\hline 1.5 & $99.84 \%$ & $99.90 \%$ & $98.37 \%$ & 1.5 & $99.78 \%$ & $99.70 \%$ & $95.61 \%$ \\
\hline 1.6 & $99.88 \%$ & $99.96 \%$ & $99.02 \%$ & 1.6 & $99.84 \%$ & $99.85 \%$ & $97.11 \%$ \\
\hline 1.7 & $99.91 \%$ & $99.98 \%$ & $99.41 \%$ & 1.7 & $99.88 \%$ & $99.92 \%$ & $98.11 \%$ \\
\hline 1.8 & $99.93 \%$ & $99.99 \%$ & $99.65 \%$ & 1.8 & $99.90 \%$ & $99.96 \%$ & $98.76 \%$ \\
\hline 1.9 & $99.95 \%$ & $100.00 \%$ & $99.79 \%$ & 1.9 & $99.93 \%$ & $99.98 \%$ & $99.19 \%$ \\
\hline 2.0 & $99.96 \%$ & $100.00 \%$ & $99.87 \%$ & 2.0 & $99.94 \%$ & $99.99 \%$ & $99.47 \%$ \\
\hline
\end{tabular}




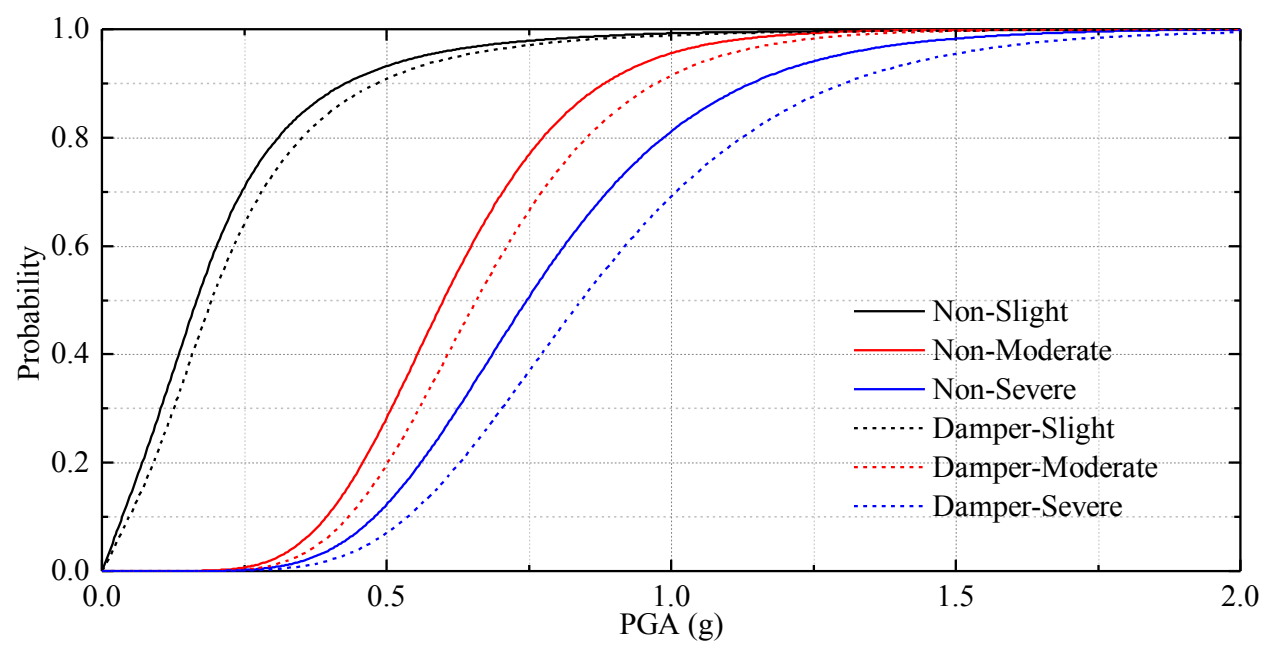

Figure 5: Fragility curves of the cabinets with and without dampers

\section{SHAKE TABLE TESTS}

Shake table tests are also conducted to validate the effectiveness of this method. Two types of cabinet layout are tested and shown in Figure 6. Three sets of three-dimensional ground motions at three different PGA levels are input. The PGA at $0.20 \mathrm{~g}, 0.40 \mathrm{~g}$ and $0.62 \mathrm{~g}$ are tested [21]. The acceleration amplitude at three directions are set as $X: Y: Z=1.00: 0.85: 0.65$. Iro $\boldsymbol{A}$ blocks are placed in the cabinets to simulate the floating rolics. The test phenomenon presented in Figure 7. The acceleration and relativ plotted in Figure 8.

It can be seen from the phonomenon that smaller with dampers than without dampers. smaller with dampers than without dampers. (3) Less cabinet doors opened during earthquake

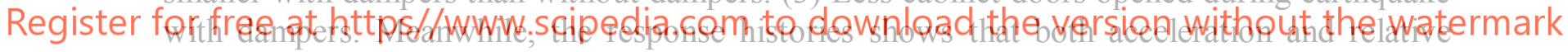
displacements can be reduced. The relative displacement is significantly reduced.

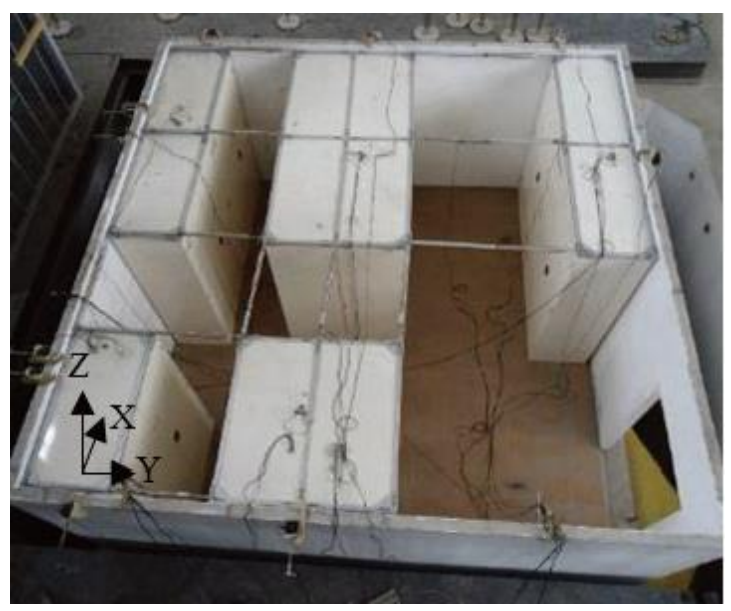

(1) Layout A

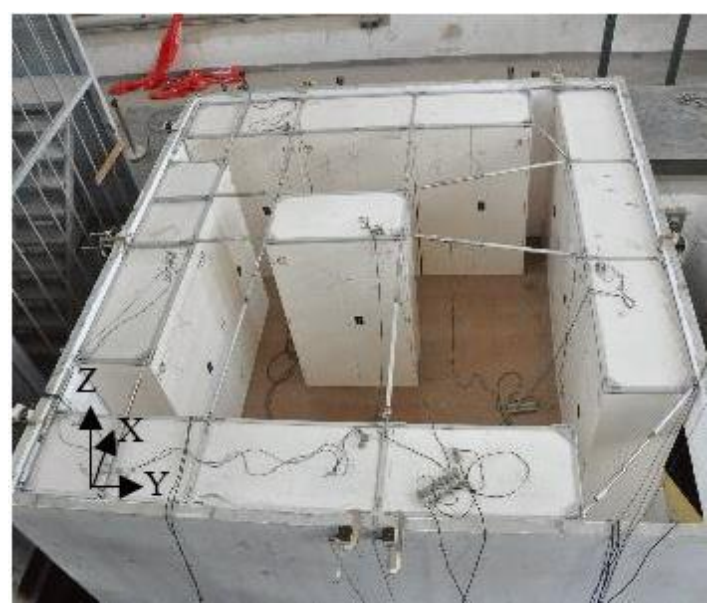

(2) Layout A

Figure 6: The shake table test layouts 


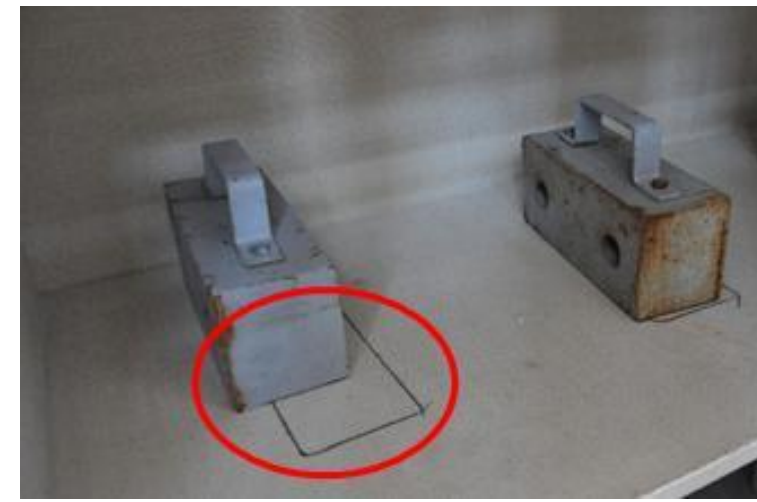

(1) Without dampers, Layout A, PGA $0.20 \mathrm{~g}$
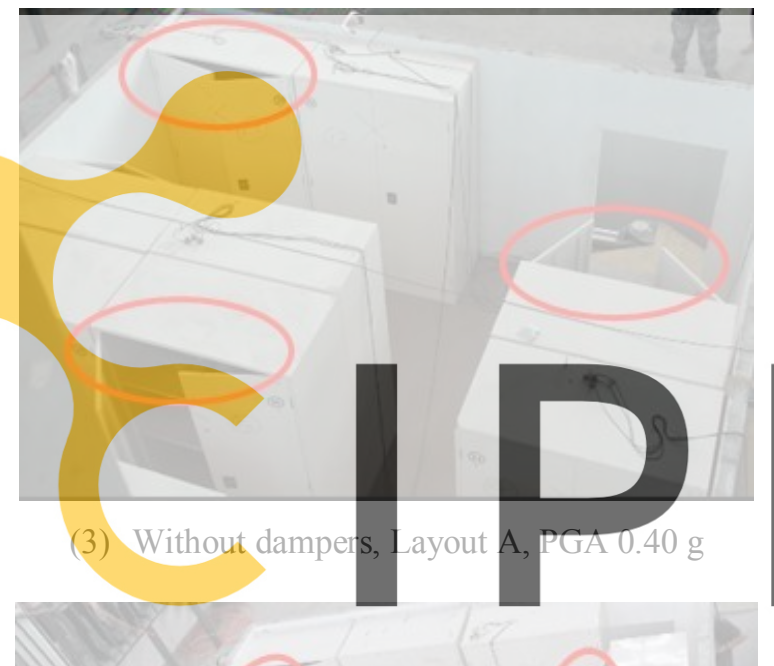

Register for free at https//www.scipedia.com to

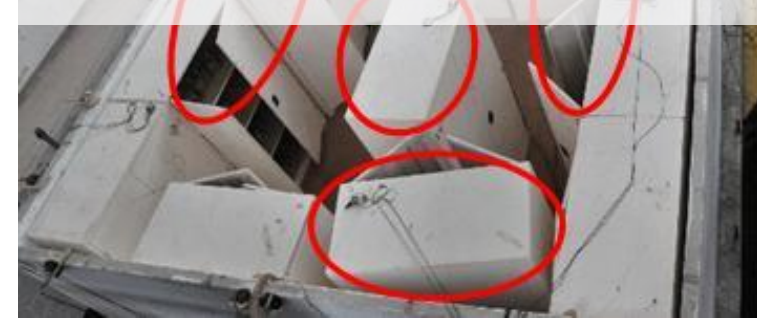

(5) Without dampers, Layout B, PGA $0.62 \mathrm{~g}$

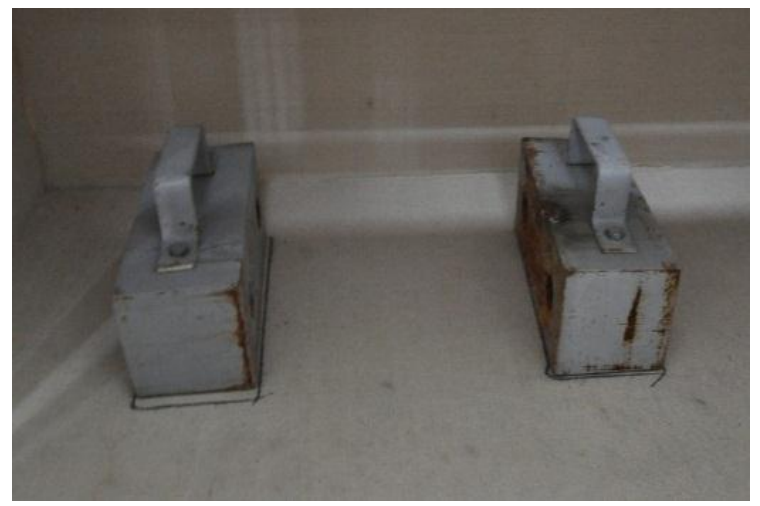

(2) With dampers, Layout A, PGA $0.20 \mathrm{~g}$

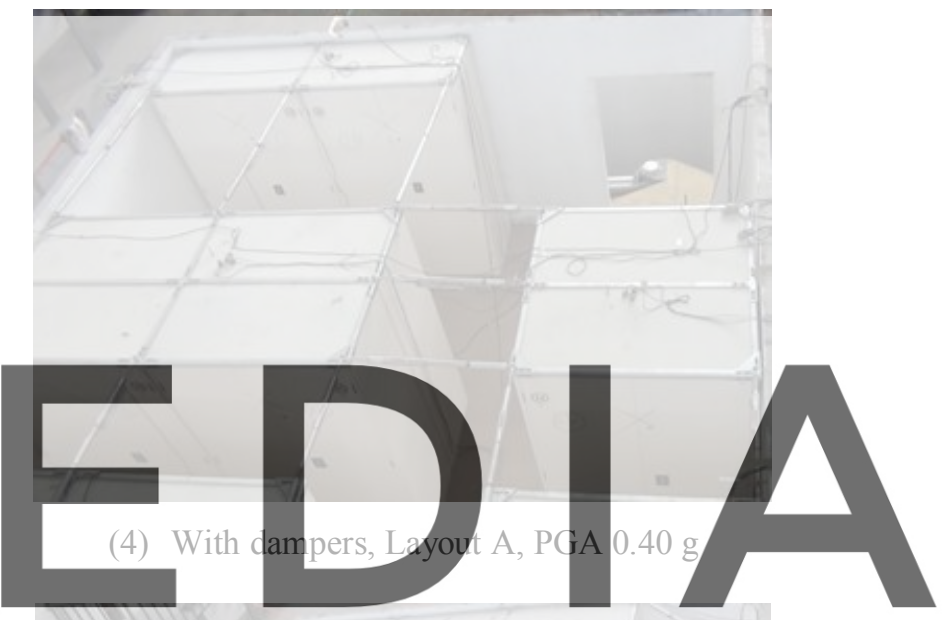

Figure 7: Traditional methods used to protect artefacts 


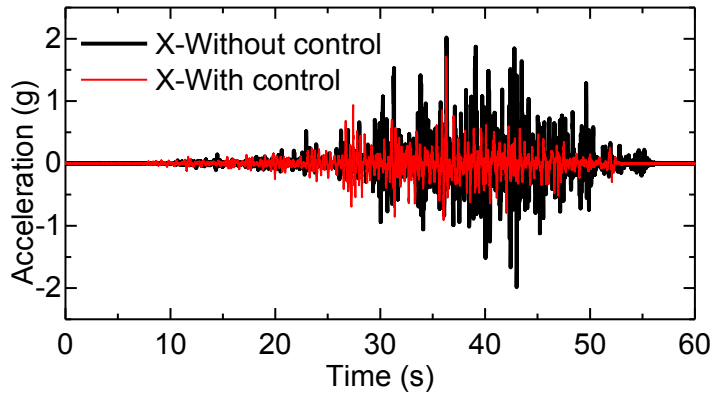

(1) $\mathrm{X}$ direction

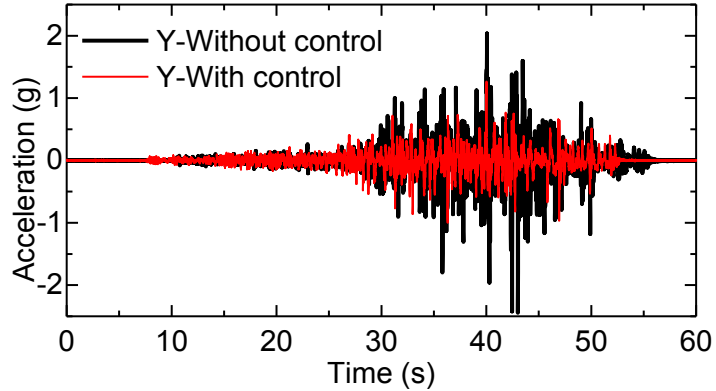

(2) $\mathrm{Y}$ direction

Figure 8: Acceleration comparison at Layout A, 4\# cabinet, $\mathrm{PGA}=0.62 \mathrm{~g}$ under Tangshan earthquake
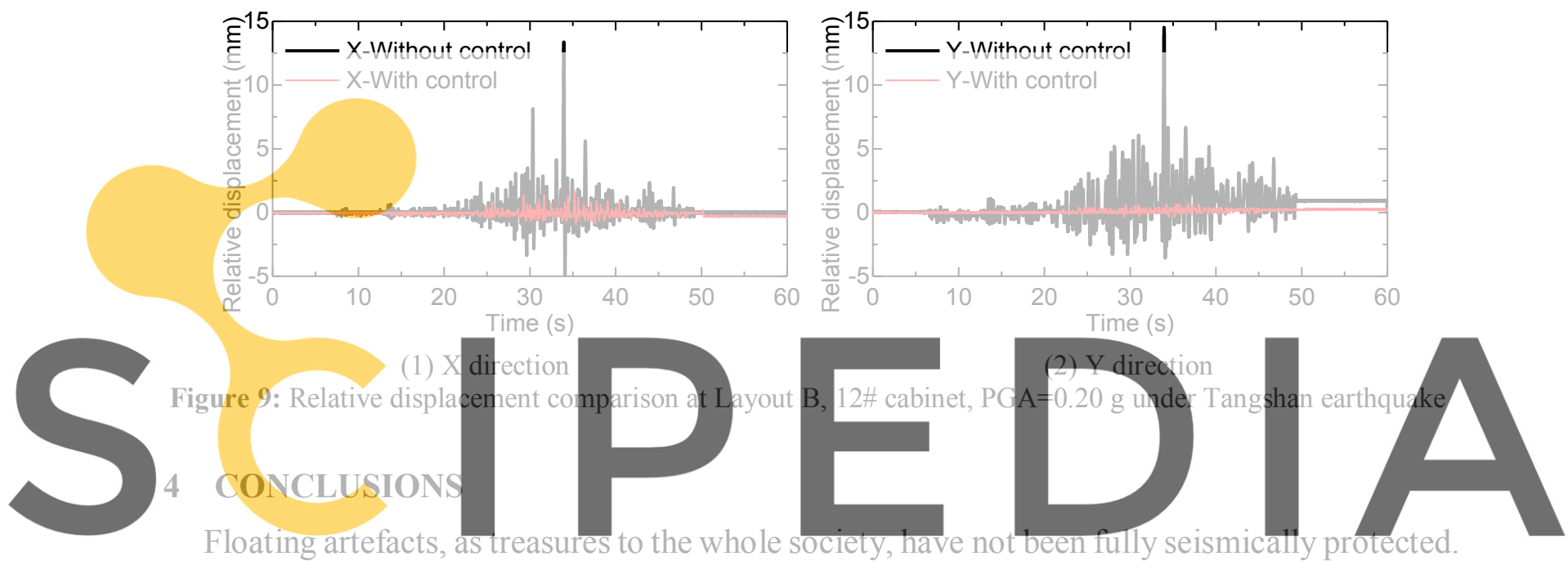

With the increasing awareness of seismic protection, measures are expected to be taken.

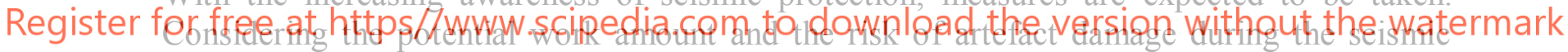

protection application, a compromise measure is proposed and researched for the cabinet stored

relics. The cabinets are connected with dampers to increase the system integrity and damping. The stored relics are not directly touched or moved. Numerical simulation and shake table tests are conducted to validate the effectiveness of this method. Fragility curves of the cabinets are plotted. Results shows that the acceleration responses and lateral sliding distances of the cabinets can be reduced. As the PGA of the input ground motion increases, the effectiveness increases.

Acknowledgements. This work is supported by Earthquake Research Fund of CEA (2019B01, 2019C09), Heilongjiang Provincial Natural Science Foundation of China (LH2019E094), Program for Innovative Research Team in China Earthquake Administration.

\section{REFERENCES}

[1] M.-T. Gong, Q. Wei, P.-L. Feng, Z.-J. Zhang, and J. Yang,"Survey on the damaged levels 
of the movable cultural relics and buildings during the 5.12 Wenchuan earthquake in Sichuan province," Sciences of Conservation and Archaeology, vol. 28, no. 4, pp. 40-47, 2016 (in Chinese).

[2] E. Cosenza, L. Di Sarno, G.Maddaloni, G.Magliulo, C. Petrone, and A. Prota, "Shake table tests for the seismic fragility evaluation of hospital rooms," Earthquake Engineering \& Structural Dynamics, vol. 44, no. 1, pp. 23-40, 2015.

[3] L. Di Sarno, C. Petrone, G. Magliulo, and G. Manfredi, "Dynamic properties of typical consultation room medical components," Engineering Structures, vol. 100, pp. 442-454, 2015.

[4] C. Petrone, L. Di Sarno, G. Magliulo, and E. Cosenza, "Numerical modelling and fragility assessment of typical freestanding building contents," Bulletin of Earthquake Engineering, vol. 15, no. 4, pp. 1609-1633, 2017.

[5] C. C. Spyrakos, C. A.Maniatakis, and I.M. Taflampas, "Application of predictive models to assess failure of museum artifacts under seismic loads," Journal of Cultural Heritage, vol. 23, pp. 11-21, 2017.

[6] T. Neurohr and G. McClure, "Shake table testing of museum display cases," Canadian Journal of Civil Engineering, vol. 35, no. 12, pp. 1353-1364, 2008

[7] Q. Zhou, W. M. Yan, and J. B. Ji, "Experimental study on aseismic behaviors of a freestanding cultural relic supported by traditional methods," Sciences of Conservation and Archaeology, vol. 27, no. 2, pp. 63-72, 2015 (in Chinese).

[8] FEMA, FEMA E-74: Reducing the Risks of NonstructuralEarthquake Damage - A Practical Guide, 2012.

[9] D. Konstantinidis a freestanding laborator Structural Dynamics, vol. 38, no. 6, pp. 827-848, 2009. body systems," Earthquake Engineering \& Structural Dynamics, vol. 46, no. 9, pp. 1391 -

Register for freenąhittps//www.scipedia.com to download the version without the watermark

[11] M. P. Singh and L. M. Moreschi, "Optimal placement of dampers for passive response control," Earthquake Engineering \& Structural Dynamics, vol. 31, no. 4, pp. 955-976, 2002.

[12] Xiaoqing, Ning, et al. "Seismic Protection of Cabinet Stored Cultural Relics with Silicone Dampers." Shock and Vibration 2018(2018):1-15.

[13]L. M. Zhu, Seismic Control and Optimization Design of Large-Span Space Structures with Viscous Dampers, China Academy of Building Research, 2007.

[14]Z.-D. Xu, Y.-P. Shen, and H.-T. Zhao, "A synthetic optimization analysis method on structures with viscoelastic dampers," Soil Dynamics and Earthquake Engineering, vol. 23, no. 8, pp. 683-689, 2003.

[15]D. L. Garc'ia, "A simple method for the design of optimal damper configurations in MDOF structures," Earthquake Spectra, vol. 17, no. 3, pp. 387-398, 2001.

[16]K. Yusuke, I. Kazuyuki, and T. Kenzo, "Use of adhesive mats to protect cultural properties from fall down during earthquakes," Proc of Urban Cultural Heritage Disaster Mitigation, vol. 2, pp. 85-90, 2008.

[17]B. Myslimaj, S. Gamble, D. Chin-Quee et al., "Base isolation technologies for seismic protection of museum artifacts," Quee, 2003. 
[18]I. Cali'o and M.Marletta, "Passive control of the seismic rocking response of art objects," Engineering Structures, vol. 25,no. 8, pp. 1009-1018, 2003.

[19]L. Berto, T. Favaretto, and A. Saetta, "Seismic risk mitigation technique for art objects: Experimental evaluation and numerical modelling of double concave curved surface sliders," Bulletin of Earthquake Engineering, vol. 11, no. 5, pp. 1817-1840, 2013.

[20]J. Podany, "An overview of seismic damage mitigation for museums," in Proceedings of the International Symposium on Advances of Protection Devices for Museum Exhibits, Beijing, China, 2015.

[21] GB50011-2010, Code for Seismic Design of Buildings, 2010 (in Chinese).
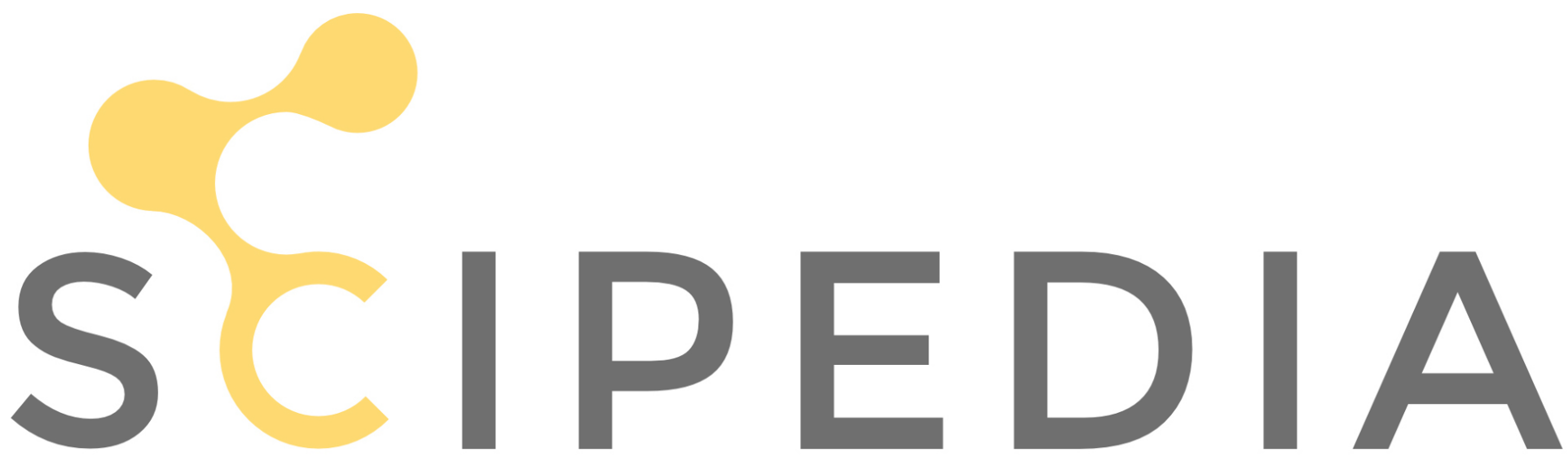

Register for free at https//www.scipedia.com to download the version without the watermark 